\title{
Producción de Biogás y Enmiendas Orgánicas a Partir del Residuo Olivícola (Alperujo)
}

\author{
María T. Varnero, Karina Galleguillos, Darío Guerrero y Javiera Suárez \\ Universidad de Chile, Facultad de Ciencias Agronómicas, AGRIMED, Casilla 1004, Santiago-Chile. \\ (e-mail: mvarnero@gmail.com; kgalleguillos@gmail.com; dguerrero10@yahoo.com; \\ javiera.suarez@gmail.com)
}

Recibido Ene. 14, 2014; Aceptado Mar. 5, 2014; Versión final recibida May. 4, 2014

\begin{abstract}
Resumen
Se desarrolló un sistema combinado de digestión anaeróbica-aeróbica para optimizar la producción de biogás e integrar la estabilización del digestato. En digestores tipo batch, a $30^{\circ} \mathrm{C}$, se usaron mezclas de residuos de "alperujo" y de hortalizas para establecer relaciones $\mathrm{C} / \mathrm{N}$ de $30 / 1$; con y sin inclusión de inoculantes metanogénicos. Después de 72 días, el sistema sin inoculantes, produce biogás de baja calidad que no supera el $13 \%$ de metano $\left(\mathrm{CH}_{4}\right), 60 \%$ de dióxido de carbono $\left(\mathrm{CO}_{2}\right)$ y un $8 \%$ de gases traza. En cambio, con inoculantes, se obtiene biogás con un $69 \%$ de $\mathrm{CH}_{4} ; 26 \%$ de $\mathrm{CO}_{2}$ y un $3 \%$ de gases traza, e inicio de la metanogénesis de 20 días, favoreciendo la producción de metano. El período de estabilización del digestato mediante compostaje es menor que la muestra de control, obteniéndose un producto con óptimos estándares para uso agrícola.
\end{abstract}

Palabras clave: biogás, digestato, digestión anaeróbica, compostaje, digestión aeróbica

\section{Biogas Production and Organic Amendments from Olive Processing Wastes (Alperujo)}

\begin{abstract}
A system combining anaerobic and aerobic phases for sludge degradation and biogas production was developed. The anaerobic phase was done in a batch type pilot digesters at $30^{\circ} \mathrm{C}$, with mixtures of residue from the oil industry, called "alperujo", and other vegetable waste to obtain $\mathrm{C} / \mathrm{N}$ ratios of $30 / 1$, with and without inclusion of methanogenic inoculants. After 72 days, the process without inoculant generated poor quality biogas that did not exceed $13 \%$ methane $\left(\mathrm{CH}_{4}\right)$, with $60 \%$ carbon dioxide $\left(\mathrm{CO}_{2}\right)$ and $8 \%$ trace gases. In contrast, the average composition of biogas produced by treatment with inoculants was about $70 \% \mathrm{CH}_{4}$, $26 \% \mathrm{CO}_{2}$ and $3 \%$ trace gases, and the methanogenic phase took 20 days to start, favoring the production of methane. The digestate composting period is less than the control sample, obtaining a product with optimum standards for agricultural use.
\end{abstract}

Keywords: biogas, digestate, anaerobic digestion, composting, aerobic digestión 


\section{INTRODUCCIÓN}

La producción de aceite de oliva es una actividad que está muy desarrollada en los países mediterráneos. Los principales productores de aceite de oliva en todo el mundo son España (38\%), Italia (22\%), Grecia (17\%) y en menor medida Turquía, Túnez, Siria, Marruecos, Portugal, Argelia y Jordania. Se espera que aumente el suministro de aceite en un futuro próximo, debido a la puesta en marcha de nuevas plantaciones en los países productores fuera de la Unión Europea. Entre estos países, especialmente Chile y Nueva Zelanda, tienen una ventaja comparativa con respecto a otros competidores y han registrado en los últimos años un aumento de la superficie de plantación de aceitunas. Chile tiene condiciones climáticas y fitosanitarias adecuadas para el cultivo del olivo, lo que ha permitido el desarrollo de esta especie entre las regiones de Arica a Bío-Bío. La superficie nacional plantada en 2010 fue de 24.000 ha, lo que corresponde al $0,3 \%$ de la superficie mundial. Se estima que el $20 \%$ de la superficie total plantada se destina a la elaboración de aceitunas de mesa y el resto, a la producción de aceite de oliva. Con esta superficie, la producción de aceite de oliva en Chile llegó a 12.000 toneladas en 2010 (0,3 \% de la producción mundial), estimándose una proyección de 35.000 toneladas para el año 2020 (Sudy y Cortés, 2012).

La extracción industrial del aceite de oliva genera una elevada cantidad de residuos y subproductos que requieren una gestión adecuada para minimizar su impacto ambiental (Pozzi et al, 2010). En la industria olivícola, han surgido nuevas tecnologías en el proceso de extracción de aceite de oliva, en el cual, además de aceite, se produce un residuo denominado "alperujo". Esta modificación, representa un problema a la hora de disponer los importantes volúmenes de residuo que se generan. En consecuencia, resulta necesario buscar alternativas para el tratamiento de estos subproductos. Por un lado, es posible destinar el "alperujo" a la cogeneración de energías renovables mediante combustión anaeróbica (biogás). Sin embargo, luego de la obtención de biogás, es necesario disponer los nuevos residuos (digestato) de manera que no ocasionen daño al medio ambiente. El digestato es un producto semi-estabilizado que tiene el aspecto de lodo con alto contenido de humedad y diversas propiedades físicas y químicas que impiden su incorporación directa al suelo; dentro de éstas, se destaca la presencia de elementos fitotóxicos (polifenoles hidrosolubles), elevada relación carbono/nitrógeno, alto contenido de sales solubles y elevado contenido de aceite (Alburquerque et al, 2006; Tortosa et al, 2012). Es posible, terminar de estabilizar el digestato mediante compostaje, obteniendo un producto final inocuo, que puede ser utilizado como acondicionador orgánico, mejorando las propiedades físicas del suelo.

La estabilización del "alperujo" mediante procesos de compostaje es una técnica bien conocida que permite convertir este residuo, en una enmienda para su uso como fertilizante orgánico (Alburquerque et al, 2006; Alburquerque et al., 2007; Cegarra et al.,2006; Filippin et al., 2012; Tortosa et al., 2012; Varnero et al, 2011). Las experiencias realizadas que utilizan digestión anaerobia son escasas (Borja et al., 2006; Roig et al., 2006; Rincón y Borja, 2012) y casi inexistente la que USA acoplamiento sucesivo de ambos métodos, anaeróbico y aeróbico, para producir biogás y un residuo orgánico estable y maduro para uso agrícola. Por otro lado, como se mencionó anteriormente, el "alperujo" presenta compuestos aromáticos, como fenoles, y ácidos grasos de largas cadenas que pueden ser tóxicos para las bacterias metanogénicas, afectando el proceso de digestión anaeróbica que reduce los contenidos de materia orgánica en los residuos, produciendo así biogás (Blika et al, 2009). Es por ello, que es necesario evaluar un pre-tratamiento que elimine dichos compuestos, como la dilución de sólidos o la utilización de microorganismos que degraden previamente el residuo, disminuyendo la toxicidad para las bacterias metanogénicas. El objetivo de esta investigación fue desarrollar un sistema combinado para el tratamiento de estos residuos con alta carga orgánica, que integre fases de degradación anaeróbica y aeróbica, con inoculantes metanogénicos incorporados, para optimizar la producción de biogás y estabilizar mediante compostaje el digestato generado en metanogénesis, el cual, se puede utilizar como acondicionador físico o enmienda orgánica del suelo.

\section{MATERIALES Y MÉTODO}

El estudio se realizó en la planta piloto del Campus Antumapu, de la Facultad de Ciencias Agronómicas de la Universidad de Chile. Las materias primas utilizadas fueron residuos de la industria olivícola "alperujo" y hortaliza. Se realizó una caracterización química de estos residuos (Tabla 1), y se preparó con ellos una mezcla en forma proporcional para obtener una relación carbono/nitrógeno (C/N) de 30/1.

Tabla 1. Caracterización química de los residuos orgánicos (materias primas).

\begin{tabular}{|l|c|c|c|c|}
\hline \multicolumn{1}{|c|}{ Residuos } & Sólidos Totales (\%) & Sólidos Volátiles (\%) & $\mathrm{C} / \mathrm{N}$ & $\mathrm{pH}$ \\
\hline Alperujo & 57 & 93,1 & 79,6 & 6,0 \\
\hline Hortalizas & 15 & 75,6 & 12,1 & 6,5 \\
\hline
\end{tabular}




\section{Digestión anaeróbica}

Se trabajó con digestores Batch de $60 \mathrm{~L}$ de capacidad, manteniendo temperaturas de $30^{\circ} \mathrm{C}$. La temperatura se controló mediante un termostato Campini, conectado a un calefactor que estaba inmerso en un contenedor con agua, dentro del cual se sumergieron los digestores. Se prepararon las mezclas de residuos con $8 \%$ de sólidos totales, conformadas por "alperujo" (27\%) y residuo de hortalizas (68\%); además, se consideró la inclusión de bacterias metanogénicas en base a guano de bovino (5\%), por lo tanto, se dispuso de dos tratamientos, con y sin inoculante (T1 y T0), con tres repeticiones. Se monitoreo diariamente la temperatura del contenedor con agua y el biogás generado. Se determinó al inicio y término de la digestión, sólidos totales, sólidos volátiles, relación $\mathrm{C} / \mathrm{N}$, conductividad eléctrica y pH.

\section{Digestión aeróbica}

Con el digestato obtenido en la fase anaeróbica (Tabla 2), se elaboraron pilas de compostaje, de forma piramidal (Fig.1) de $1 \mathrm{~m}^{3}$ con volteos manuales periódicos. Además se dispuso de pilas control, conformadas con materias primas frescas (Tabla 1). Se realizaron controles de humedad y temperatura interna de las pilas cada 7 días. A los productos estabilizados por compostaje se determinó $\mathrm{pH}$, conductividad eléctrica (CE), materia orgánica (MO), relación carbono/nitrógeno $(\mathrm{C} / \mathrm{N})$, estabilidad biológica y madurez química mediante fitotoxicidad en germinación de semillas de rabanito (Raphanus sativus var. Cherry belle). (Raj y Antil, 2011; Varnero et al., 2007; Barrena et al., 2006).

Tabla 2. Caracterización de las mezclas usadas en la preparación de las pilas de compost.

\begin{tabular}{|l|c|c|c|c|c|}
\hline & \multicolumn{5}{|c|}{ Parámetros } \\
\hline Residuos & Sólidos totales (\%) & Materia Orgánica (\%) & C/N & C.E.dS $/ \mathrm{m}$ & $\mathrm{pH}$ \\
\hline T0 (Materias frescas) & 47 & 92,6 & $30 / 1$ & 3,1 & 6,2 \\
\hline T1 (digestato) & 53 & 90,0 & $48 / 1$ & 2,75 & 6,6 \\
\hline
\end{tabular}
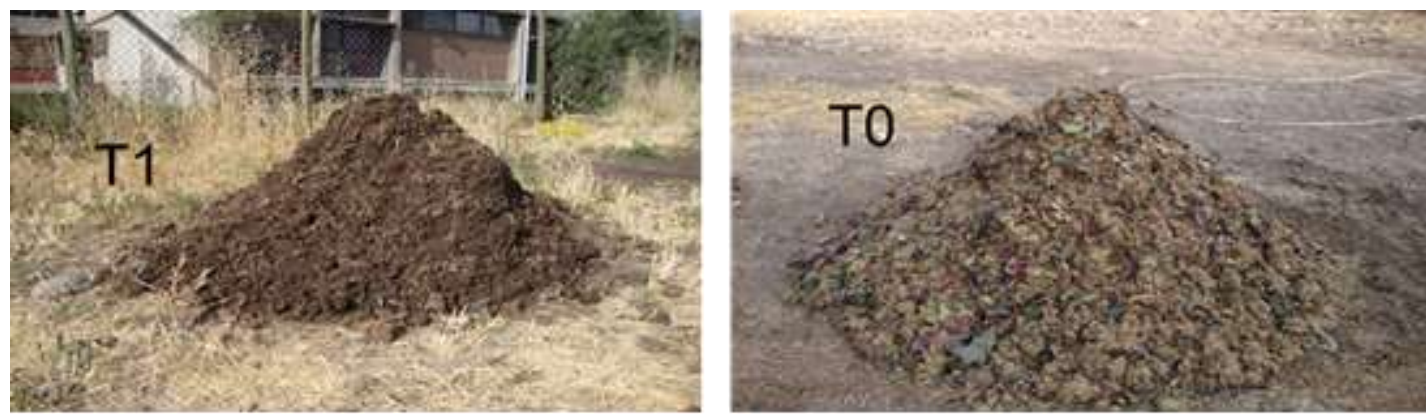

Fig. 1: Pilas de compostaje: a base de digestato (T1) y con materias primas frescas (T0)

\section{RESULTADOS Y DISCUSIÓN}

\section{Digestión anaeróbica}

Los resultados obtenidos indican que en el tratamiento sin inoculante (Tabla 3), a pesar de las condiciones mesofílicas $\left(30^{\circ} \mathrm{C}\right)$, presenta un tiempo de retención hidráulico $(\mathrm{TRH})$ de 72 días; generando un biogás de baja calidad, con valores promedio de metano $\left(\mathrm{CH}_{4}\right)$ que no superan el $13 \%$; de dióxido de carbono $\left(\mathrm{CO}_{2}\right)$ del orden del $60 \%$ y un $8 \%$ de gases traza, tales como sulfuro de hidrógeno $\left(\mathrm{H}_{2} \mathrm{~S}\right)$, nitrógeno $\left(\mathrm{N}_{2}\right)$, oxígeno $\left(\mathrm{O}_{2}\right)$ y monóxido de carbono (CO). En cambio, en el tratamiento con inoculante (Tabla 4) se obtiene un biogás con valores promedio de un $69 \%$ de $\mathrm{CH}_{4} ; 26 \%$ de $\mathrm{CO}_{2}$ y $3 \%$ de gases traza, junto con tiempos de inicio de la fase metanogénica en torno a los 20 días. La producción media de biogás por $\mathrm{kg}$ de materia prima fue de $0,03 \mathrm{~L}$ para T0 y $0,3 \mathrm{~L}$ paraT1; con un rendimiento total de biogás para T0 de $0.7 \mathrm{~L}$ y para T1 de 9,3L.

Al respecto, se ha descrito (Hilbert, 2000; FAO, 2011) que en el caso de sistemas Batch o discontinuos, el TRH coincide con el tiempo de permanencia del sustrato orgánico (materias primas) dentro del digestor. El TRH está íntimamente ligado con dos factores: el tipo de sustrato y la temperatura interna del sistema. La selección de una mayor temperatura implica una disminución del TRH, en la medida que se disponga del sustrato adecuado para el desarrollo de bacterias metanogénicas. Con relación al tipo de sustrato (Vargas, 2005; FAO, 2011), generalmente los materiales con mayor proporción de carbono retenido en moléculas resistentes como celulosa demandará mayores TRH para ser totalmente digeridos. Por otra parte, en un sistema continuo, el límite mínimo del TRH está dado por la tasa de reproducción de las bacterias 
metanógenicas debido a que la continua salida de efluente del digestor, extrae una determinada cantidad de bacterias que se encuentran en el efluente. Esta extracción debe ser compensada por las bacterias que permanecen dentro del digestor (Hilbert, 2000; Insam et al, 2009). En sistemas Batch, la inclusión de inóculos metanogénicos, en base a guano de bovino, constituye un aporte tanto de bacterias metanogénicas como del sustrato adecuado para la reproducción y crecimiento microbiano.

Tabla 3: Composición del biogás generado: sin inclusión de inoculantes metanogénicos.

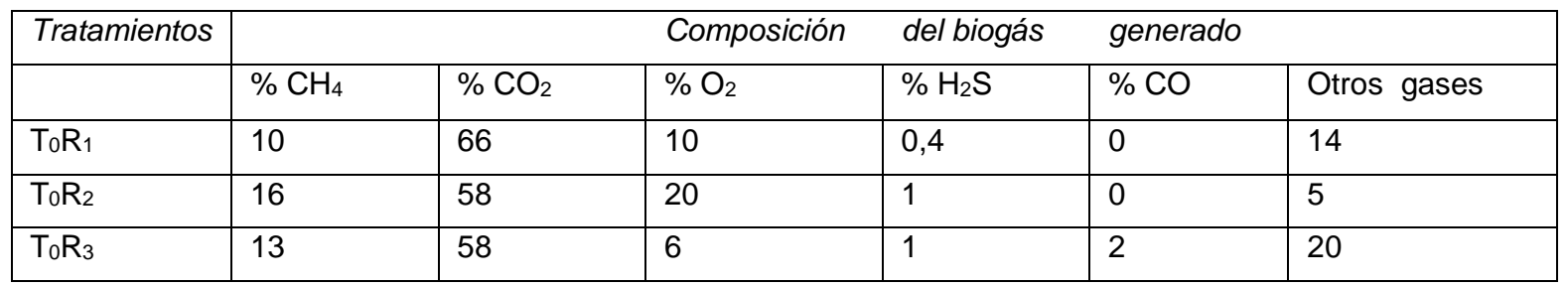

Tabla 4: Composición del biogás generado: con inclusión de inoculantes metanogénicos.

\begin{tabular}{|l|l|l|l|l|l|l|}
\hline Tratamientos & \multicolumn{5}{|c|}{ Composición } & \multicolumn{2}{c|}{ del biogás } & \multicolumn{2}{c|}{ generado } \\
\hline & $\% \mathrm{CH}_{4}$ & $\% \mathrm{CO}_{2}$ & $\% \mathrm{O}_{2}$ & $\% \mathrm{H}_{2} \mathrm{~S}$ & $\% \mathrm{CO}$ & Otros gases \\
\hline $\mathrm{T}_{1} \mathrm{R}_{1}$ & 71 & 27 & 1.6 & 0 & 0 & 0.4 \\
\hline $\mathrm{T}_{1} \mathrm{R}_{2}$ & 72 & 26 & 1.7 & 0 & 0 & 0.3 \\
\hline $\mathrm{T}_{1} \mathrm{R}_{3}$ & 64 & 24 & 2.1 & 0 & 0 & 9.9 \\
\hline
\end{tabular}

\section{Digestión aeróbica}

A través de la medición periódica de la temperatura interna de las pilas, se aprecia que los tratamientos analizados se diferenciaron en la duración de las distintas etapas del proceso de compostaje (Fig.2).

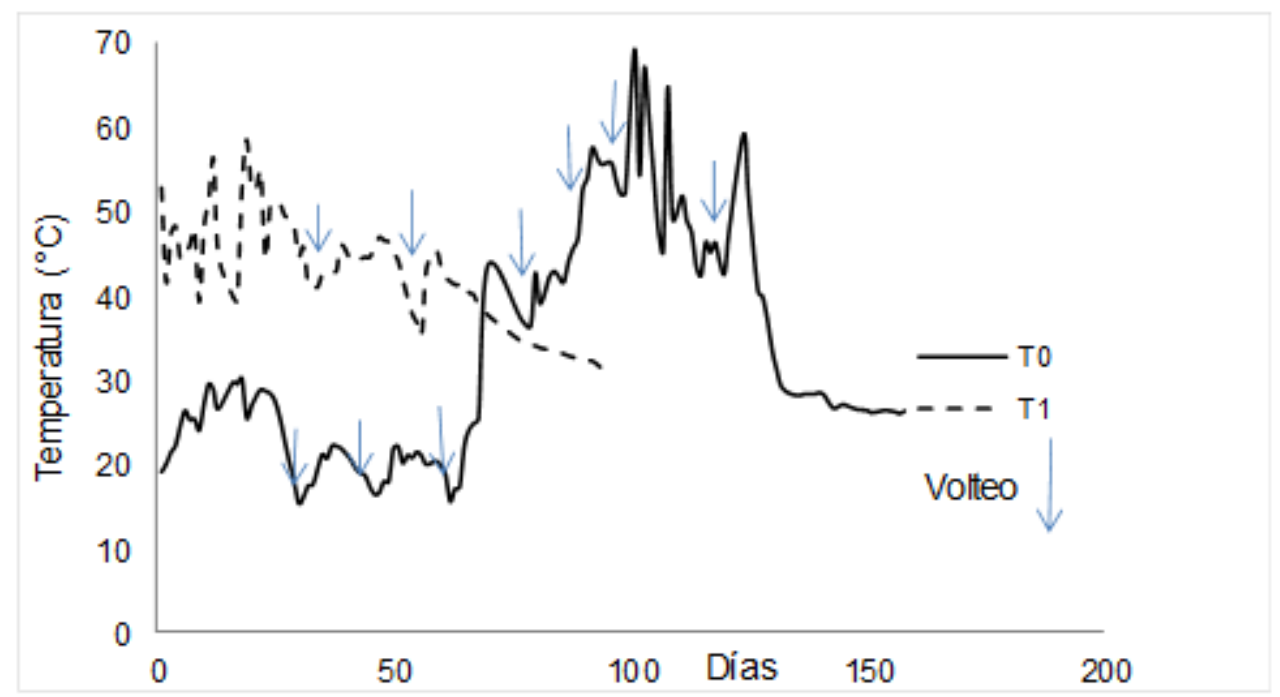

Fig. 2. Evolución de la temperatura interna de las pilas de Compost, conformadas con materias primas frescas (T0) y con digestato (T1), durante el proceso de compostaje (Valores promedios).

El tratamiento control (T0), tuvo una etapa inicial mesofílica de una duración de 80 días promedio entre las tres repeticiones, evidenciando el difícil manejo de este residuo, dado en primer lugar por su alto porcentaje de compuestos lipídicos y ácidos orgánicos, y segundo, por su alta susceptibilidad a la compactación, originada por el pequeño tamaño de partículas, escasa porosidad y elevado contenido de humedad, como indican diversos autores (Alburquerque et al, 2004; Cegarra et al, 2006; Tortosa et al, 2012). Luego comenzó la etapa termofílica que duró en promedio 45 días. En cambio, el tratamiento T1 no tuvo etapa mesofílica. El material extraído de los biodigestores ingresó al proceso de compostaje con una temperatura termofílica de $52,9^{\circ} \mathrm{C}$. La etapa termofílica en este tratamiento duró 51 días. En ambos tratamientos la temperatura se mantuvo entre el rango termofílico óptimo señalado por la Normativa Chilena de Compost 2880 (INN, 2004) de 45 a $65^{\circ} \mathrm{C}$, y se constató una gran actividad biológica por parte de los microorganismos termofílicos que biodegradaron las fracciones orgánicas de menor estabilidad, tales como productos celulósicos, hemicelulósicos y productos ricos en azúcares y proteínas. El porcentaje del contenido de agua 
en los dos tratamientos se mantuvo entre un $45-55 \%$ durante el proceso de compostaje. Se observó que el tiempo de compostaje requerido para obtener un producto final maduro y estable en el digestato, se reduce respecto del control (Fig. 2). Al finalizar el proceso de compostaje, que tiene lugar cuando la temperatura interna de las pilas de compost, es similar a la temperatura del aire, se determinó en ambos tratamientos, una reducción en la relación carbono-nitrógeno (Tabla 5). En T1 la disminución de la relación C/N fue mayor que en T0 posiblemente por una mayor degradación de los compuestos orgánicos sometidos a procesos de degradación anaeróbica y aeróbica. Además, el contenido de materia orgánica en ambos tratamientos disminuye con el tiempo; reducción asociada probablemente con las transformaciones que se producen en la etapa termófila (Cegarra et al., 2006), debido principalmente a la respiración microbiana oxidativa. Por otra parte, tanto en el tratamiento T0 y T1 los valores correspondientes a desprendimiento de $\mathrm{CO}_{2}$ están por debajo de $8 \mathrm{mg} \mathrm{C}-\mathrm{CO}_{2} / \mathrm{g} \mathrm{MO} /$ día, valor que exige la normativa chilena para considerar un compost estabilizado y maduro. Por lo tanto, es posible afirmar que ambos tratamientos tienen una baja actividad microbiológica, dando cuenta de que los microorganismos han agotado el stock de materia orgánica fácilmente descomponible (Varnero et al, 2007; Barrena et al, 2006).

Tabla 5. Caracterización química y biológica de los materiales compostados.

\begin{tabular}{|l|l|l|l|}
\hline Parámetros & $T 0$ & $T 1$ & Rango Norma INN (2004) \\
\hline $\mathrm{pH}$ & 6,5 & 7,1 & $5,5-8,5$ \\
\hline C.E. $\left(\mathrm{dSm}^{-1}\right)$ & 1,24 & 0,99 & Clase $\mathrm{A}<3$; Clase $\mathrm{B}<8$ \\
\hline Humedad $(\%)$ & 36 & 31 & $30-45$ \\
\hline Materia Orgánica (\%) & 62,4 & 67,7 & $>20$ \\
\hline Relación C/N & 29,7 & 24,3 & Clase A $\leq 25 / 1 ;$ Clase B $\leq 30 / 1$ \\
\hline Desprendimiento $\mathrm{CO}_{2}$ (mgC-CO $/ \mathrm{CO}_{2} / \mathrm{g} \mathrm{MO/día)}$ & 0,51 & 0,09 & $\leq$ a 8 \\
\hline Germinación semillas rabanito $\%)$ & 91 & 97 & $\geq$ a 80 \\
\hline
\end{tabular}

Las pruebas de germinación indican que las sustancias fitotóxicas han desaparecido después de este período, observándose (Tabla 5) que el $91 \%$ de las semillas germinó en el tratamiento control después del quinto mes. En cambio en T1, a los tres meses de compostaje, germina el $97 \%$ de las semillas. En ambos casos, las evidencias son claras sobre la posibilidad de utilizar estos materiales tratados como enmiendas orgánicas, para el desarrollo de cultivos. Además, los valores de $\mathrm{pH}$ medidos al comienzo de cada tratamiento (Tabla 2) indican que el tratamiento control (T0) tenía un $\mathrm{pH}$ promedio de 6,2; lo que corresponde a un nivel moderadamente ácido. Esto obedecería principalmente a la presencia de ácidos orgánicos presentes en el "alperujo" (Alburquerque et al, 2004; Tortosa et al, 2012). En el caso del digestato, se determinó un valor inicial de 6,6; lo que indicaría que el proceso de biogás se llevó a cabo bajo condiciones controladas para la fermentación anaeróbica. Al final del proceso de compostaje, se observa un $\mathrm{pH}$ ligeramente ácido de 6,5 para T0 y neutro $(7,1)$ para T1 (Tabla 5). En ambos tratamientos disminuyó la conductividad eléctrica, proporcionando un residuo sin restricciones como fertilizante. El compostaje de digestato genera un compost clase A; en cambio, con el "alperujo" sin tratamiento previo, el producto compostado es clase B (Tabla 5).

\section{CONCLUSIONES}

El uso de inoculantes microbianos en el proceso de digestión metanogénica, permite que los períodos de obtención de metano sean menores, optimizando así el proceso e incrementando la producción de metano. El digestato residual estabilizado mediante compostaje, genera un compost clase $A$, pudiendo utilizarse con fines agronómicos sin restricciones. Se reduce el periodo de estabilización y maduración en la pila construida a base de digestato, respecto de la pila testigo conformada con materias primas frescas.

\section{AGRADECIMIENTOS}

Los autores agradecen al Ministerio de Energía por el financiamiento otorgado para la realización de este trabajo a través del proyecto "Biogás y Aplicaciones"

\section{REFERENCIAS}

Alburquerque, J. A., J.Gonzálvez y D. García, Agrochemical characterisation of alperujo, a solid by-product of the phases centrifugation method for olive oil extraction. Bioresource Technology. 91: 195-200, (2004).

Alburquerque, J.A. y otros tres autores, Effects of bulking agent on the composting of "alperujo", the solid byproduct of the two-phase centrifugation method for olive oil extraction, Process Biochemistry: 41, 127-132, (2006). 
Alburquerque, J.A. y otros tres autores, Effects of a compost made from a solid by-product ("alperujo") of a two-phase centrifugation system for olive oil extraction and cotton gin waste on growth and nutrients content ryegrass (Lolium perenne L.), Bioresource Technology: 98, 940 - 945, (2007).

Barrena R., F. Vázquez y A. Sánchez, The use of respiration indices in the composting process: a review. Waste Managent and Research 24: 37-47, (2006).

Blika, P.S. y otros tres autores, Anaerobic digestion of olive mill wastewater. Global Nest Journal. Vol. 11 (3): 364-372. (2009).

Borja, R., Rincón, B. y Raposo, F., Anaerobic biodegradation of two-phase olive mill solid wastes and liquid effluents: Kinetic studies and process performance. Journal of Chemical Technology and Biotechnology, 81 (9), pp. 1450-1462. (2006).

Cegarra, J. y otros cuatro autores, Effects of the forced ventilation on composting of a solid olive-mill byproduct ("alperujo") managed by mechanical turning. Waste Management, 26 (12), pp. 1377-1383. (2006).

FAO, Manual de Biogás. Santiago de Chile: Organización de las Naciones Unidas para la Alimentación y la Agricultura. Oficina Regional para América Latina y el Caribe. 315p. (2011) Disponible en: http://www.fao.org/alc/file/media/pubs/2011/manual_biogas.pdf. Acceso 2 de abril (2014).

Filippin, A.E y otros cuatro autores, Evolución de la lignina y celulosa durante el compostaje de mezclas de alpeorujo. Argentina y Ambiente 374-379. (2012).

Hilbert, J., Manual para la producción de biogás. Instituto de Ingeniería Rural. INTA, Castelar, Argentina, 57p. (2000).

Insam, H., I. Franke-Wittle y M. Goberna, Microbes in aerobic and anaerobic waste treatment. In: Microbes at work. From wastes to resources. Insam, H., I. Franke-Wittle y M. Goberna (Eds). Pp. 1-34, Springer, Heidelberg, Dordrecht London, New York, (2009).

NCh 2880-2004, Norma Chilena de Compost 2880-2004: Compost - Clasificación y requisitos, Instituto Nacional de Normalización (INN), 23 p, Santiago, Chile (2004).

Pozzi, M. y otros tres autores, Posibilidad de usar el alpechín en fertilización de tierras agrícolas, Información Tecnológica: 21(4), 117-123 (2010).

Raj, D y R.S. Antil, Evaluation of maturity and stability parameters of composts prepared from agro-industrial wastes. Bioresource Technology. 102: 2868-2873. (2011).

Rincón B. y R. Borja, Influence of Substrate Concentration on the Anaerobic Degradability of Two-Phase Olive Mill Solid Waste: A Kinetic Evaluation Biogas. Dr Sunil Kumar (Ed.), ISBN: 978-953-51-0204-5, InTech, 408 p. (2012). Disponible en: http://www.intechopen.com/books/biogas/influence-of-substrate-concentrationon-the-anaerobic-degradability-of-two-phase-olive-mill-solid-wa. Acceso: 2 de abril (2014).

Roig, A., M.L.Cayuela, y M. A. Sánchez-Monedero, An overview on olive mil wastes and their valorisation methods. Waste Management. Vol. 26: 960 - 969. (2006).

Sudy, A. y P. Cortés, Aceite de Oliva. Oficina de Estudios y Política Agraria (ODEPA) (2012). Disponible en: http://www.odepa.gob.cl/odepaweb/publicaciones/doc/2394.pdf. Acceso: 15 de diciembre (2013).

Tortosa, G. y otros tres autores, The production of comercial organic amendments and fertilisers by composting of two phase olive mil waste ("alperujo"). Journal of Cleaner Production 26: 48 - 55 (2012).

Vargas, G., Estudio de la generación de biogás a partir de la sinercia en mezclas de algas marinas, biodegrades en un sistema de bioconversión anaerobias de dos etapas. Memoria de Título. Universidad Católica de Temuco. Facultad de Ciencias. Temuco, Chile, 95p. (2005).

Varnero, M.T., C. Rojas y R. Orellana, Índices de fitotoxicidad de residuos orgánicos durante el compostaje, Revista de la Ciencia del Suelo y Nutrición Vegetal, 7 (1), 28 - 37 (2007).

Varnero, M.T., K. Galleguillos y R. Rojas, Sistemas de compostaje para el tratamiento de alperujo. Información Tecnológica: 22(5), 49-56 (2011). 